\title{
CONF- $9505309--1$
}

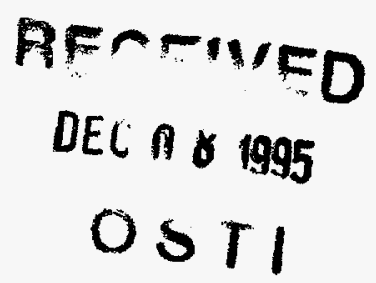

Determination of N-Nitrosodimethylamine at Part-Per-Trillion Levels in Drinking Waters and Contaminated Groundwaters

Bruce A. Tomkins ${ }^{1}$, Wayne H. Griest, and Cecil E. Higgins

Organic Chemistry Section, Chemical and Analytical Sciences Division Oak Ridge National Laboratory ${ }^{2}$

P. O. Box 2008, Oak Ridge, TN 37831-6120

FAX: (615)-576-7956

Presented to the $18^{\text {th }}$ Annual EPA Conference on Analysis of Pollutants in the Environment Marriott Waterside Hotel, Norfolk, VA

May 3-4, 1995

\section{DISCLAIMER}

\begin{abstract}
This report was prepared as an account of work sponsored by an agency of the United States Government. Neither the United States Government nor any agency thereof, nor any of their employees, makes any warranty, express or implied, or assumes any legal liability or responsibility for the accuracy, completeness, or usefulness of any information, apparatus, product, or process disclosed, or represents that its use would not infringe privately owned rights. Reference herein to any specific commercial product, process, or service by trade name, trademark, manufacturer, or otherwise does not necessarily constitute or imply its endorsement, recommendation, or favoring by the United States Government or any agency thereof. The views and opinions of authors expressed herein do not necessarily state or reflect those of the United States Government or any agency thereof.
\end{abstract}

1 To whom correspondence should be addressed

2 This research was sponsored by the U. S. Army, Program Manager Rocky Mountain Arsenal, under U. S. Department of Energy Interagency Agreement No. 1989-H077-A1, U. S. Department of Energy contract no. DE-AC05-84OR21400 with Lockheed Martin Energy Systems, Inc. 


\section{DISCLAMMER}

Portions of this document may be illegible in electronic image products. Images are produced from the best available original docoment. 
Determination of N-Nitrosodimethylamine at Part-Per-Trillion Levels in Drinking Waters and Contaminated Groundwaters ${ }^{1}$

Bruce A. Tomkins², Wayne H. Griest, and Cecil E. Higgins

Organic Chemistry Section, Chemical and Analytical Sciences Division, Oak Ridge National Laboratory, P. O. Box 2008, Oak Ridge, TN 37831-6120

FAX: (615)-576-7956

\section{Introduction}

$\mathrm{N}$-nitrosodimethylamine (NDMA, CAS registry number [62-75-9]) is a highly carcinogenic manufacturing by-product of unsymmetrical dimethyl hydrazine (1,1dimethylhydrazine), a component of rocket fuel ${ }^{1}$. Prior disposal practices, now strongly discouraged, resulted in the contamination of groundwater near certain military installations with both species. The current regulatory threshold promulgated by the U. S. Environmental Protection Agency (EPA) for NDMA in surface waters designated for drinking is $0.7 \mathrm{ng}$ NDMA/L (0.7 pptr) $\mathrm{L}^{2}$. Existing procedures for determining NDMA in aqueous samples typically employ dichloromethane extraction followed by concentration to a final volume of 1 $\mathrm{mL}$, and gas chromatographic analysis of a $2 \mu \mathrm{L}$ aliquot of concentrate using either a nitrogenphosphorus detector (NPD) $)^{3,4,5}$, mass spectrometric detector ${ }^{6,7,8,9}$, or chemiluminescent nitrogen detector (CLND) ${ }^{1,10,11,12,13}$. Such a protocol does not permit detection of NDMA at the desired health-based criterion unless high-resolution mass spectrometric (HRMS) detectors are employed ${ }^{6,14}$.

The analytical procedure described in this work employed an initial solid-phase extraction of groundwater samples with a preconditioned Empore ${ }^{\otimes} \mathrm{C}_{18}$ disk, used to remove interfering neutral species including di-isopropylmethane phosphonate (DIMP), prior to continuous overnight extraction of the filtrate with highest-purity dichloromethane ${ }^{15}$. The dichloromethane extract is concentrated to a final volume of $1 \mathrm{~mL}$; the residues from a $200 \mu \mathrm{L}$ aliquot of the concentrate are injected onto a gas chromatographic column using a short-path thermal desorber. NDMA is collected at the head of the column near ambient temperature (without cryotrapping), eluted in the conventional manner, and detected using a CLND. The reporting limit for this procedure, 2 ng NDMA/L groundwater, was calculated using two statistically-unbiased procedure ${ }^{16,17}$. The certified range for this procedure is 2 to $40 \mathrm{ng}$ NDMA/L groundwater.

A related procedure permitted unattended analysis of samples for NDMA concentrations exceeding $100 \mathrm{ng}$ NDMA/L groundwater. The sample preparation is the same as that described above; however, $2 \mu \mathrm{L}$ aliquots of dichloromethane concentrates are injected onto the gas

1 This research was sponsored by the U. S. Army, Program Manager Rocky Mountain Arsenal, under U. S. Department of Energy Interagency Agreement No. 1989-H077-A1, U. S. Department of Energy contract no. DE-AC05-84OR21400 with Martin Marietta Energy Systems, Inc.

2 To whom correspondence should be addressed 


\section{Determination of $\mathbf{N}$-Nitrosodimethylamine at Part-Per-Trillion Levels in Drinking Waters and Contaminated Groundwaters}

(continued)

chromatographic column using an automatic sampler.

\section{Procedure and Considerations}

Analytical procedures capable of achieving the stated regulatory criterion must satisfy numerous challenges, whose nature and their resolution are addressed as follows:

- Not all water supplies are suitable for preparing either standards or spiked samples because small quantities of NDMA, frequently exceeding the regulatory limit, may be present. Bottled HPLC-grade water, which typically contains $0.5-1 \mathrm{ng}$ NDMA/L, is usually satisfactory. Water obtained from "on-demand" high-purity stills is satisfactory only if the unit is equipped with both reverse-osmosis and UV purification stages.

- NDMA is suitable for neither purge-and-trap analysis or solid-phase extraction with reversed-phase media. This analyte's miscibility with water precludes most extraction procedures with the exception of overnight continuous extraction with dichloromethane and, possibly, extraction with carbonaceous sorbents such as Ambersorb ${ }^{672^{6}}$.

- High concentrations of neutral species which might interfere with the NDMA determinations were expected in the groundwater samples (normally $1 \mathrm{~L}$ volumes employed). These compounds may be removed conveniently with a "pre-extraction" employing a $\mathrm{C}_{18}$ Empore $^{\circledR}$ disk conditioned with methanol and water in the usual manner.

- The continuous extraction followed by the usual Kuderna-Danish concentration step can produce an excessive background unless the highest purity solvent, such as Burdick \& Jackson " $\mathrm{GC}^{2 "}$ dichloromethane, is employed.

- Most commercially-available detectors, with the exception of some mass spectrometric detectors, cannot provide adequate sensitivity with a typical 1 or $2 \mu \mathrm{L}$ sample injection volume. A practical alternative is use a short-path thermal desorber (SPTD) to inject the residues of up to $200 \mu \mathrm{L}$ sample. Aliquots of the dichloromethane extract, not exceeding $100 \mu \mathrm{L}$, are spiked onto a dual-stage carbon sorbent trap; the solvent is removed gently with highest-purity helium. If this procedure is repeated, the residues from up to $200 \mu \mathrm{L}$ of concentrated extract (one-fifth of the volume available) are concentrated on the trap, and may be injected onto a gas chromatographic column.

- The gas chromatographic column employed must act as both a trap for NDMA and a separation medium to separate the analyte from other components of the extract. In practice, a commercially-available Rtx ${ }^{\oplus}-200$ column $(0.53 \mathrm{~mm}$ i.d. $\times 30 \mathrm{~m}, 3 \mu \mathrm{m}$ film thickness) is suitable for both tasks over many $(>1000)$ injections. Cryotrapping is not necessary if the initial column oven temperature is maintained at $35^{\circ} \mathrm{C}$ during short-path thermal desorption. Thick-film Stabilwax ${ }^{\oplus}$ columns of similar dimensions and film thickness, while better-known to most chromatographers, exhibit significant column bleed 
Determination of N-Nitrosodimethylamine at Part-Per-Trillion Levels in Drinking Waters and Contaminated Groundwaters

(continued)

during the short-path thermal desorption (performed at $150^{\circ} \mathrm{C}$ ), and are therefore unsuitable for this application.

- Nitrogen phosphorus detectors (NPD) do not possess the selectivity required for determining NDMA at nanogram levels from dichloromethane extracts of aqueous samples. The chemiluminescent nitrogen detector (CLND) provides both the sensitivity and selectivity required. The two-step operating mechanism of the CLND, which explains its selectivity, includes cleavage of the $\mathrm{N}-\mathrm{N}$ single bond at low furnace temperature (typically $250^{\circ} \mathrm{C}$ ) followed by the chemiluminescent reaction of the NO. free radical with ozone produced in the reaction chamber to form $\mathrm{NO}_{2}{ }^{*}$. When $\mathrm{NO}_{2}{ }^{*}$ degrades to its corresponding ground state, a photon of red light is produced. Under these conditions, this mechanism therefore predicts no expected interferences for the detection of nitrosamines.

- The procedure as described clearly does not lend itself to automated unattended operation, primarily because large sample volumes are needed to achieve the desired sensitivity. For aqueous samples whose NDMA concentrations are known or expected to exceed approximately $100 \mathrm{ng}$ NDMA/L, an automatic sampler can replace the shortpath thermal desorber. The two procedures working in tandem permit the determination of NDMA over four orders of magnitude in drinking waters or contaminated groundwaters.

\section{Method Certification and Calculation of the Detection Limit Using the Short-Path Thermal Desorber or Automatic Sampler}

The performance of the procedure sketched above was evaluated using protocol developed by the U. S. Army Rocky Mountain Arsenal (RMA) and the U. S. EPA ${ }^{16,17}$. Briefly, the calibration curve was generated using two independently-prepared sets of standards (concentration range 2-160 ng NDMA/mL dichloromethane) analyzed on two separate days. The detector response was plotted against the mass of NDMA expected (in pg). The resulting calibration curve was tested statistically for "lack of fit" compared to linear models with a zero or nonzero intercept. The result was a linear calibration with nonzero intercept, as expected. Two sets of synthetic groundwater samples containing 2-40 ng NDMA/L were generated and analyzed on two separate days. The dichloromethane extract for each sample was concentrated to a final volume of $1 \mathrm{~mL}$, of which $200 \mu \mathrm{L}$ were ultimately analyzed as described above. Figure 1 shows the respective chromatograms for a synthetic groundwater sample fortified to $10 \mathrm{ng}$ NDMA/L (1A), a synthetic groundwater sample fortified to $2 \mathrm{ng} \mathrm{NDMA/L} \mathrm{(1B),} \mathrm{and} \mathrm{a} \mathrm{synthetic} \mathrm{groundwater}$ blank (1C). A peak was clearly observed for NDMA at the $2 \mathrm{ng} / \mathrm{L}$ concentration (Figure 1B) with an area greater than that observed in the synthetic groundwater blank.

The "target" or "expected" mass of NDMA was calculated for each sample, then compared to the "found" mass actually observed, as show in Table 1. A linear regression 


\section{Determination of N-Nitrosodimethylamine at Part-Per-Trillion Levels in Drinking Waters and Contaminated Groundwaters}

(continued)

analysis was performed on the data described in Table 1; both upper and lower confidence bands were constructed about the resulting line. The results are shown graphically in Figure 2; the region near the origin is enlarged and depicted in Figure 3.

The "Method Reporting Limit" (MRL), a statistically-based detection limit, was calculated using the data presented in Table 1, and the calculated linear regression line and confidence bands, as depicted in Figures 2 and 3. The MRL value is located by the following four-step procedure: (1) calculate and plot a regression line, representing the "found" vs "target" concentrations, with appropriate two-sided $90 \%$ confidence limits for a predicted observation; (2) locate the intercept of the upper $90 \%$ predictive confidence limits with the $y$-axis ("found" concentrations); (3) draw a horizontal line from this intercept until it intersects the lower $90 \%$ predictive confidence limits; and (4) draw a vertical line from the intercept described in (3) to the $\mathrm{x}$-axis ("target" concentrations). This intersection with the $\mathrm{x}$-axis is the MRL. Additional details describing the calculation of the MRL are presented elsewhere ${ }^{18}$. The slope of the certification line given in Figure 2, 0.499, may be taken as the overall recovery of NDMA using the procedure (i.e., $50 \%$ recovery). In this particular case, the calculated MRL was $348.37 \mathrm{pg}$ NDMA, as shown in Figure 3. This value may be readily converted to approximately $2 \mathrm{ng}$ NDMA/L of synthetic groundwater knowing (a) the NDMA mass, (b) the aqueous sample volume (1 L prepared, $0.9 \mathrm{~L}$ analyzed), (c) the dichloromethane concentrate final volume $(1 \mathrm{~mL})$, and (d) the volume of (c) used for the determination (200 $\mu \mathrm{L})$.

$$
\frac{348.37 \mathrm{pg} \mathrm{NDMA}}{200 \mu \mathrm{L} \text { concentrate }} * \frac{1000 \mu L \text { concentrate }}{0.9 \mathrm{~L} \text { sample }} * \frac{n g N D M A}{1000 \mathrm{pg} \mathrm{NDMA}}=1.93 \mathrm{ng} \mathrm{NDMA} / \mathrm{L}=M R L
$$

The "Method Detection Limit" (MDL) was calculated by analyzing eight synthetic groundwater samples (seven required) fortified to $10 \mathrm{ng}$ NDMA/L in the manner described above. The standard deviation, which was calculated for both seven and eight replicates, was then multiplied by the appropriate one-tailed Student's-t statistic for $99 \%$ confidence. The resulting value is the MDL, which, in this case, was approximately 2 ng NDMA/L, as shown in Table 2. These calculations also satisfy an additional criterion ${ }^{16}$, in that the magnitude of the MRL (1.93 ng NDMA/L, discussed previously) should be equal to or larger than that of the MDL (1.9 ng NDMA/L, given in Table 2).

The MRL, MDL, and overall method recovery were calculated for higher concentrations of NDMA in water in a similar manner, using an automatic sampler to inject $2 \mu \mathrm{L}$ aliquots of dichloromethane concentrate from $1 \mathrm{~L}$ synthetic groundwater samples fortified to $100-2000 \mathrm{ng}$ NDMA/L. The "Target" and "Found" NDMA concentrations from this method certification are presented in Table 3. When the MRL was calculated using all of the data values given in Table 3 , a concentration of $272 \mathrm{ng} \mathrm{NDMA} / \mathrm{mL}$ extract, corresponding to $302 \mathrm{ng}$ NDMA/L groundwater was obtained, considerably greater than the desired $100 \mathrm{ng}$ NDMA/L. The NDMA concentration in the original groundwater sample is calculated knowing the extract concentration (measured), and the volumes of the aqueous sample and dichloromethane concentrate $0.9 \mathrm{~L}$ and $1 \mathrm{~mL}$, 
Determination of N-Nitrosodimethylamine at Part-Per-Trillion Levels in Drinking Waters and Contaminated Groundwaters

(continued)

respectively), since

$$
\frac{272 n g N D M A}{m L \text { concentrate }} * \frac{1 m L \text { concentrate }}{0.9 L \text { groundwater }}=302 n g N D M A / L=M R L
$$

The data set was then truncated by removing the "found" concentrations observed at $2000 \mathrm{ng}$ NDMA/L, as recommended ${ }^{16}$. The MRL calculated using the truncated data set was $103 \mathrm{ng}$ NDMA/mL extract, corresponding to $114 \mathrm{ng}$ NDMA/L groundwater, was obtained. This latter value was close enough to the TRL to be useful; further truncation of the data set was unwarranted. The estimated overall method recovery, based on the slope of the MRL certification graph, was $71 \%$.

The MDL was calculated using eight replicate spiked synthetic groundwater samples (minimum seven required) fortified to $500 \mathrm{ng}$ NDMA/L and the same protocol described previously. The resulting data, presented in Table 4, demonstrate that the calculated MDL, 87 ng NDMA/L, satisfied the criteria for acceptance presented previously.

\section{Application of the "Low-Level" Procedure to the Determination of NDMA in Drinking Water}

NDMA was quantitated in three sources of drinking water (four replicates each) and a synthetic groundwater blank using the procedure sketched above. The short-path thermal desorber was used exclusively to inject aliquots of the extract concentrate because the NDMA concentrations expected were below $100 \mathrm{ng}$ NDMA/L. Typical chromatograms are presented in Figure 4, where chromatograms (A) and (B) represent extracts from drinking waters showing 9 and $2 \mathrm{ng}$ NDMA/L, respectively, and chromatogram $(\mathrm{C})$ is the synthetic groundwater blank containing less than 2 ng NDMA/L. The NDMA concentration data, which typically exhibit an RSD $<20 \%$, are summarized in Table 5. Values marked with a "J" qualifier exhibit calculated concentrations below the MRL of $2 \mathrm{ng}$ NDMA/L.

Application of the "Low-Level" and "High-Level" Procedures to the Determination of NDMA in Raw and Treated Contaminated Groundwaters

Four sets of raw and treated groundwaters contaminated with NDMA were analyzed using both NDMA procedures described previously. Because the samples were submitted "blind" (i.e., no concentration estimates were provided) and the expected concentrations ranged between 100 5000 ng NDMA/L, all extracts were analyzed initially using the "high-level" procedure featuring the automatic sampler. In this manner, untreated or mildly-treated groundwaters could be identified, quantified, and set aside. Figure 5 shows chromatograms from an untreated groundwater (A), a groundwater which had received some treatment (B), and a synthetic groundwater blank (C). Extracts which exhibited concentrations below $100 \mathrm{ng}$ NDMA/L were 


\section{Determination of $\mathrm{N}$-Nitrosodimethylamine at Part-Per-Trillion Levels in Drinking Waters and Contaminated Groundwaters}

(continued)

re-analyzed using the "low-level" procedure, where the short-path thermal desorber was used for sample injection. The chromatograms in Figure 6 show two treated groundwaters (6A and 6B) and a groundwater blank (6C).

The groundwater samples analyzed in this study were "split" and evaluated by an independent collaborating commercial laboratory using a related analytical method. All data is presented in Table 6, and generally shows good to excellent agreement between laboratories over a wide concentration range. The designation "12LT" means that the calculated concentration was less than the commercial laboratory's detection limit, which is $12 \mathrm{ng}$ NDMA/L.

\section{Conclusions}

The above discussion demonstrates that the short-path thermal desorber provides a simple and elegant means of injecting the residues from large volumes of organic solvent into a gas chromatograph, thereby providing sensitivity not possible with traditional injectors. Procedures employing the CLND to detect nitrosamines provide additional selectivity compared to the morecommon NPD, though less than those using high-resolution mass spectrometry. The method presented permits both a Method Reporting Limit and a Method Detection Limit of $2 \mathrm{ng}$ NDMA/L when the SPTD is in place. A traditional automatic sampler, when substituted for the SPTD, permits unattended analysis of groundwater extracts for NDMA. The MRL and MDL for the latter procedure are approximately 110 and $87 \mathrm{ng}$ NDMA/L, respectively. The procedures have been evaluated using two statistically-based protocols. The two methods taken together were used to analyze NDMA found in various treated groundwaters and drinking water, where the analyte concentrations were expected to range from "trace" (i.e., $\mu \mathrm{g} / \mathrm{L}$ ) to ultra-trace (i.e., ng/L) levels, or approximately four orders of magnitude. The results from the latter study were compared to, and largely agreed with, those obtained by a commercial analytical laboratory using a different analytical procedure.

\section{Acknowledgements}

The authors gratefully acknowledge the assistance of Mses. Suzanne B. Johnson, Patricia A. Marshall, Holly A. Marshall, and Mr. Eric Heidel (Lockheed Martin Energy Systems, Analytical Services Division, Water Preparation Laboratory) for performing the continuous extractions of samples described in this work. This research was sponsored by the U. S. Army, Program Manager Rocky Mountain Arsenal, under U. S. Department of Energy Interagency Agreement No. 1989-H077-A1, U. S. Department of Energy Contract no. DE-AC05-84OR21400 with Lockheed Martin Energy Systems, Inc. 
Determination of N-Nitrosodimethylamine at Part-Per-Trillion Levels in Drinking Waters and Contaminated Groundwaters

(continued)

Table 1. Comparison of "Target" and "Found" NDMA Masses on the Two Days of Certification Using the Short-Path Thermal Desorber as the Injector

\begin{tabular}{cccc} 
& & \multicolumn{2}{c}{ "Found" Mass of NDMA } \\
\cline { 3 - 4 } $\begin{array}{c}\text { Target NDMA } \\
\text { Concentration, ng/L }\end{array}$ & $\begin{array}{c}\text { "Target Mass" } \\
\text { NDMA, pg }\end{array}$ & Day 1 & Day 2 \\
2 & 400 & 151 & 288 \\
4 & 800 & 402 & 411 \\
10 & 2000 & 1059 & 993 \\
20 & 4000 & 2005 & 2006 \\
40 & 8000 & 4071 & 3973 \\
\hline
\end{tabular}


Determination of N-Nitrosodimethylamine at Part-Per-Trillion Levels in Drinking Waters and Contaminated Groundwaters

(continued)

Table 2. Calculation of the Method Detection Limit Using Replicate Water Samples Containing $10 \mathrm{ng}$ NDMA/L. Short-Path Thermal Desorber Used as the Injector.

Replicate Number

1

2

3

4

5

6

7

8
Calculated NDMA, ng/L

6.47

5.77

6.40

7.07

5.61

6.49

5.30

0.59

1.9

MDL, seven samples ${ }^{1}, \mathrm{ng} / \mathrm{L}$

0.63

Standard deviation, all eight samples 1.9

MDL, eight samples ${ }^{2}$

1 Student's-t value (one-tailed) at $99 \%$ confidence for seven samples (six degrees of freedom) $=3.143$

2 Student's-t value (one-tailed) at $99 \%$ confidence for eight samples (seven degrees of freedom) $=2.998$ 
Determination of N-Nitrosodimethylamine at Part-Per-Trillion Levels in Drinking Waters and Contaminated Groundwaters

(continued)

Table 3. Comparison Between the "Target" and "Found" Concentrations of NDMA When the Automatic Sampler is Used for Sample Injection

"Found" NDMA Concentration, ng/L

"Target" NDMA Concentration, ng/L

100

200

500

1000

2000
Day 1

67

147

376

745

1324
Day 2

62

120

357

796

1401 
Determination of N-Nitrosodimethylamine at Part-Per-Trillion Levels in Drinking Waters and Contaminated Groundwaters

(continued)

Table 4. Calculation of the Method Detection Limit Using Replicate Spiked Synthetic Groundwater Samples Containing 500 ng NDMA/L. Automatic Sampler Used as the Injector.

$\begin{array}{cc}\text { Replicate Number } & \text { Calculated Sample Concentration, ng/L } \\ 1 & 369 \\ 2 & 336 \\ 3 & 316 \\ 4 & 348 \\ 5 & 315 \\ 6 & 363 \\ 7 & 389 \\ 8 & 387\end{array}$

Sample standard deviation, "best" seven

samples

MDL, "best seven samples"', ng/L

84

Sample standard deviation, all eight samples

MDL, all eight samples ${ }^{2}$

1 Student's-t value (one-tailed) at $99 \%$ confidence for seven samples (six degrees of freedom) $=3.143$

2 Student's-t value (one-tailed) at $99 \%$ confidence for eight samples (seven degrees of freedom) $=2.998$ 
Determination of N-Nitrosodimethylamine at Part-Per-Trillion Levels in Drinking Waters and Contaminated Groundwaters

(continued)

Table 5. Determination of NDMA in Drinking Water, Not Corrected for Blank

Source

A

\begin{tabular}{cc} 
A & 7.9 \\
& 9.3 \\
Mean, Source A & 9.7 \\
Standard deviation, Source A & 8.4 \\
B & 8.8 \\
& 0.8 \\
\hline Mean, Source B & $1.8(\mathrm{~J})^{1}$ \\
Standard deviation, Source B & 2.6 \\
\hline C & 2.9 \\
& 2.4 \\
\hline Standard deviation, Source C & 2.4 \\
\hline Mean, Source C & 0.5 \\
\hline & 2.1 \\
& $1.8(\mathrm{~J})$ \\
& $1.6(\mathrm{~J})$ \\
& $1.5(\mathrm{~J})$ \\
& $1.7(\mathrm{~J})$ \\
& 0.3 \\
\hline & $1.5(\mathrm{~J})$ \\
\hline
\end{tabular}

1 Calculated concentration is below the MRL 
Determination of N-Nitrosodimethylamine at Part-Per-Trillion Levels in Drinking Waters and Contaminated Groundwaters

(continued)

\section{Table 6. Comparison of NDMA Determinations Performed by Two Laboratories} for Treated and Untreated Groundwater

\begin{tabular}{|c|c|c|c|c|}
\hline \multirow[b]{2}{*}{ Sampling Date } & \multirow[b]{2}{*}{ Site Designation } & \multicolumn{3}{|c|}{ NDMA, ng/L } \\
\hline & & "Laboratory A" & $\begin{array}{l}\text { ORNL, "High-Level", } \\
\text { Autosampler }\end{array}$ & $\begin{array}{l}\text { ORNL, "Low- } \\
\text { Level", SPTD }\end{array}$ \\
\hline \multirow[t]{5}{*}{$08 / 06 / 94$} & A & 280 & 320 & \\
\hline & B & 350 & 330 & \\
\hline & $\mathrm{C}$ & 78 & 41 & 83 \\
\hline & D & $12(\mathrm{LT})^{\mathrm{t}}$ & $<110(\mathrm{~J})^{2}$ & 16 \\
\hline & $\mathrm{E}$ & $12(\mathrm{LT})$ & $<110(\mathrm{~J})$ & 6 \\
\hline \multirow[t]{4}{*}{$08 / 06 / 94$} & F & 260 & $70(J)^{3}$ & 330 \\
\hline & G & $12(\mathrm{LT})$ & $<110(\mathrm{~J})$ & 100 \\
\hline & $\mathbf{H}$ & $12(\mathrm{LT})$ & $<110(\mathrm{~J})$ & 21 \\
\hline & 1 & $12(\mathrm{LT})$ & $<110(\mathrm{~J})$ & 7 \\
\hline \multirow[t]{5}{*}{$08 / 13 / 94$} & $\mathbf{J}$ & $--^{4}$ & 2900 & \\
\hline & K &.-- & 6500 & \\
\hline & $\mathbf{L}$ & --- & 6200 & \\
\hline & $\mathbf{M}$ & --- & 7000 & \\
\hline & $\mathbf{N}$ & $\ldots$ & 5400 & \\
\hline \multirow[t]{4}{*}{$08 / 12 / 94$} & 0 & 240 & 270 & \\
\hline & $\mathbf{P}$ & $12(\mathrm{LT})$ & $<110(\mathrm{~J})$ & 27 \\
\hline & $\mathbf{Q}$ & 300 & 300 & \\
\hline & $\mathbf{R}$ & 110 & 250 & \\
\hline
\end{tabular}

1 Concentration is less than (LT) the stated detection limit, $12 \mathrm{ng}$ NDMA/L, of the collaborating laboratory.

2 No peak detected at all. $110 \mathrm{ng}$ NDMA/L is the MRL; " $\mathrm{J}$ " qualifier indicates that the calculated value is below the detection limit.

3 Improper injection from the automatic sampler led to low calculated value (peak observed, but below the MRL) during the "high-level" procedure. Use data from "lowvalue" method as final.

4 Corresponding value from collaborating laboratory not available 
Determination of N-Nitrosodimethylamine at Part-Per-Trillion Levels in Drinking Waters
and Contaminated Groundwaters

(continued)

\section{FIGURE CAPTIONS}

Figure 1. Detection of NDMA in (A) synthetic groundwater sample fortified to $10 \mathrm{ng}$ NDMA/L, (B) synthetic groundwater sample fortified to 2 ng NDMA/L, and (C) synthetic groundwater blank.

Figure 2. Graphical Determination of the Method Reporting Limit (MRL) Using All of the Method Certification Data. $(--)=$ linear regression curve based on the "found" NDMA masses; $(---)=$ lower confidence limit; $(\cdots)=$ upper confidence limit; $O=$ "found" NDMA mass; $\square=$ MRL.

Figure 3. Enlargement of the Method Certification Curve Showing the Calculation of the MRL. ( $(-)=$ linear regression curve based on the "found" NDMA masses; $(--)=$ lower confidence limit; $(\cdots)=$ upper confidence limit; $O=$ "found" NDMA mass; $(--\rightarrow)=$ steps used to calculate the MRL.

Figure 4. Detection of NDMA in two sources of drinking water, (A) and (B). The corresponding synthetic groundwater blank (C) exhibits a smaller concentration of NDMA than in either source.

Figure 5. Detection of NDMA in groundwaters using the "high-level" procedure employing the automatic sampler. (A) and (B) are groundwater extracts; (C) is a synthetic groundwater blank.

Figure 6. Detection of NDMA in groundwaters using the "low-level" procedure employing the short-path thermal desorber. (A) and (B) are groundwater extracts; (C) is a synthetic groundwater blank. 
Determination of N-Nitrosodimethylamine at Part-Per-Trillion Levels in Drinking Waters and Contaminated Groundwaters

(continued)

References

1. Fine, D. H.; Rounbehler, D. P.; Rounbehler, A.; Silvergleid, A.; Sawicki, E.; Krost, K.; DeMarrais, G. A. Environ. Sci. and Tech. 1977, 11, 581-584.

2. "Water Quality Standards; Establishment of Numeric Criteria for Priority Toxic Pollutants; States' Compliance", in Federal Register December 22, 1992, 246, 60848-60918.

3. "Method 8070, Nitrosamines by Gas Chromatography", in Test Methods for Evaluating Solid Waste, Volume 1B: Laboratory Manual Physical/Chemical Methods, U. S. Environmental Protection Agency, SW-846, 3rd edition, Washington, D.C., proposed update I, November, 1990.

4. "Method 607, Nitrosamines", in Code of Federal Regulations: Protection of the Environment, 40, Part 136, October, 1984.

5. "The Determination of N-Nitrosodimethylamine and N-Nitroso-di- $n$-propylamine in Water by Gas Chromatography, Version No. 2", DataChem Laboratories, Salt Lake City, UT, June, 1990.

6. Taguchi, V. Y.; Jenkins, S. W. D.; Wang, D. T.; Palmentier, J-P. F. P.; Reiner, E. J. Canadian J. Appl. Spec. 1994, 39, 87-93.

7. Jobb, B.; Hunsiger, R.; Meresz, O.; Taguchi, V. Removal of N-Nitrosodimethylamine (NDMA) from the Osweken (Six Nations) Water Supply. Interim Report (July, 1993). Queen's Printer for Ontario, CANADA, 1993. PIBS 2687.

8. Plomley, J. B.; Koester, C. J.; March, R. E. Anal. Chem. 1994, 66, 4437-4443.

9. "The Determination of N-Nitrosodimethylamine in Water by Gas Chromatography/Mass Spectrometry Selected Ion Monitoring, Method UM34, Version 1", DataChem Laboratories, Salt Lake City, UT, October, 1992.

10. Fine, D. H.; Rounbehler, D. P.; Pellizzari, E. D.; Bunch, J. E.; Berkley, R. W.; McCrae, J.; Bursey, J. T.; Sawicki, E.; Krost, K.; DeMarrais, G. A. Bull. Env. Contamin. Toxicol. 1976, 15, 739-746.

11. Fine, D. H.; Rounbehler, D. P.; Sawicki, E.; Krost, K. Env. Sci. and Tech. 1977, 11, 577-580.

12. Fine, D. H.; Rounbehler, D. P. J. Chromat. 1975, 109, 271-279.

13. D. H. Fine; Rufeh, F.; Lieb, D.; Rounbehler, D. P. Anal. Chem. 1975, 47, 1188-1191. 
Determination of $\mathrm{N}$-Nitrosodimethylamine at Part-Per-Trillion Levels in Drinking Waters and Contaminated Groundwaters

(continued)

14. Taguchi, V. "The Determination of N-Nitrosodimethylamine (NDMA) in Water by Gas Chromatography-High Resolution Mass Spectrometry (GC-HRMS)", Environment Ontario (CANADA), Laboratory Services Branch, Quality Management Office, method catalogue code NDMA-E3291A, originally approved February 19, 1993; revised and approved April 7, 1994.

15. "Method 3520A, Continuous Liquid-Liquid Extraction", in Test Methods for Evaluating Solid Waste, Physical/Chemical Methods, SW-846, 3rd Edition, Final Update 1, U. S. Environmental Protection Agency, Washington, D. C., Revision 1, July, 1992.

16. Program Manager for Rocky Mountain Arsenal: Chemical Quality Assurance Plan. Version I, September, 1993.

17. "Appendix B to Part 136 - Definition and Procedure for the Determination of the Method Detection Limit - Revision 1.11", in Code of Federal Regulations: Protection of the Environment, 40, Parts 100 to 149, revised as of July 1, 1990.

18. Tomkins, B. A.; Merriweather, R.; Jenkins, R. A.; Bayne, C. K. J. Assoc. Off. Anal. Chem. Internat. 1992, 75, 1091-1099. 
Figun 1. Toukios shol

Top $\uparrow$

ORNL-DWG 95Z-4717
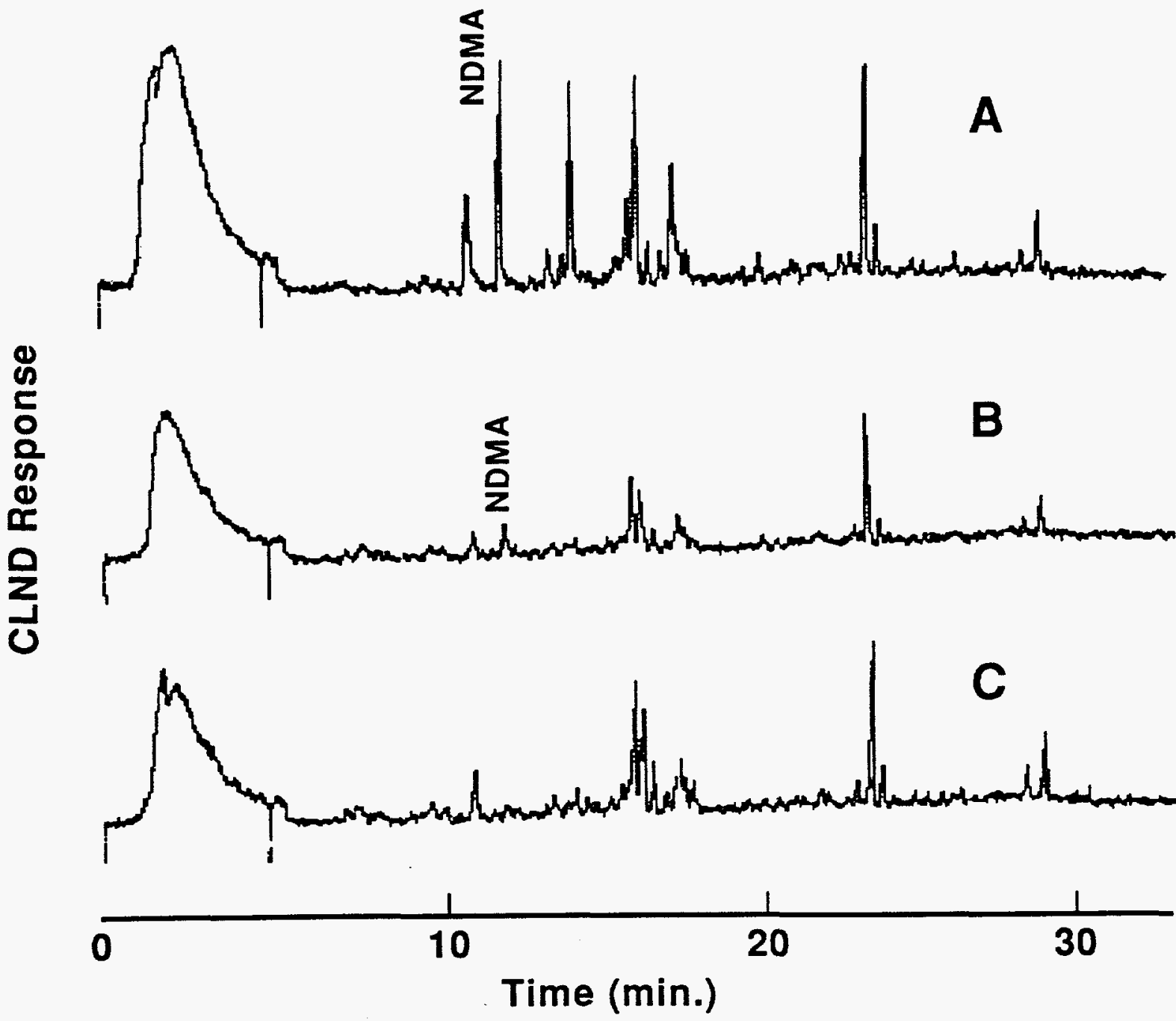
Vigurez. $\frac{T \text { lowirias st el }}{\log \rho}$

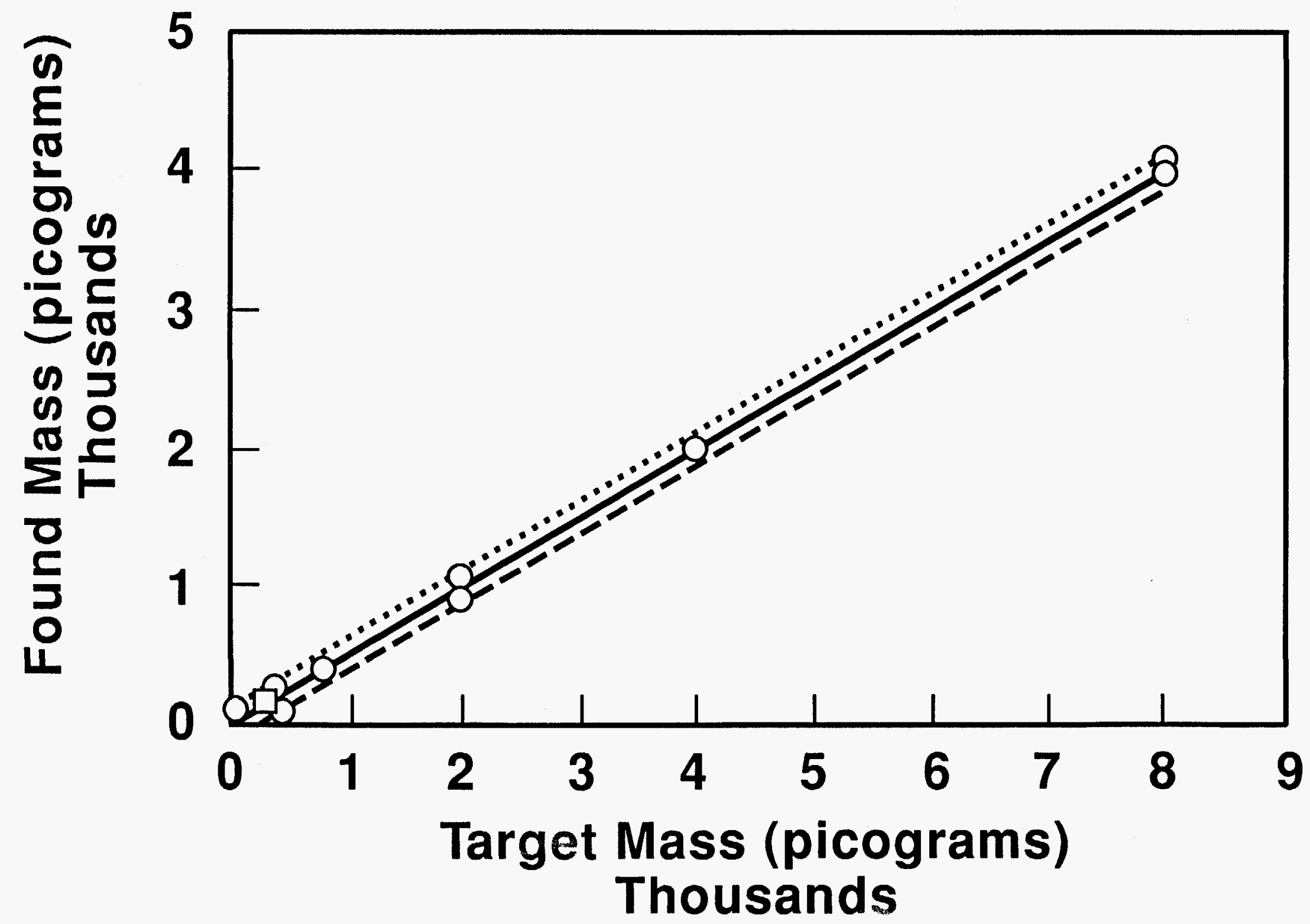




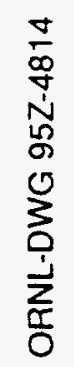

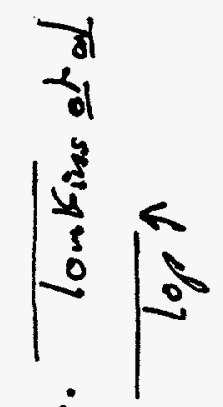

i

5

4

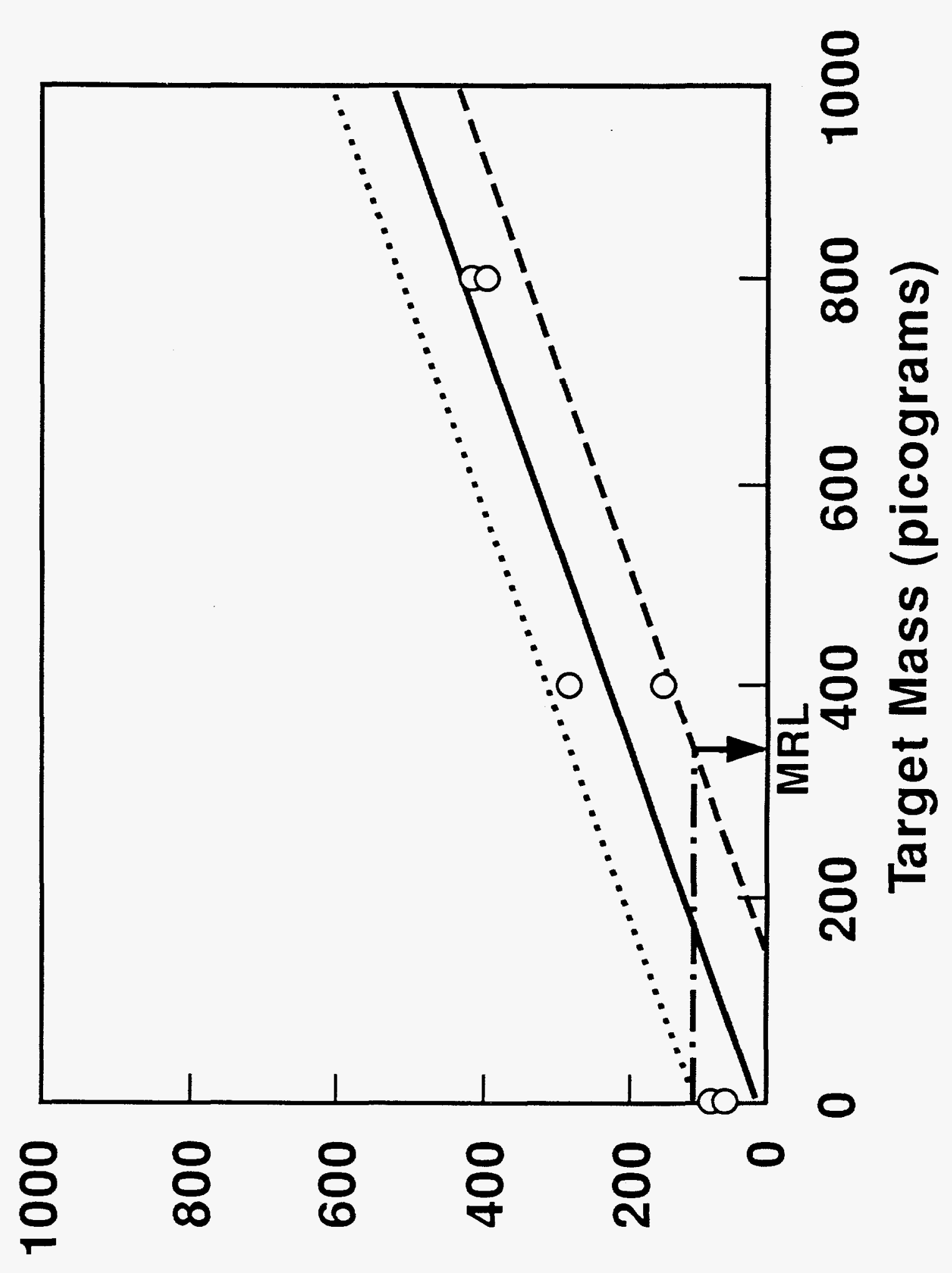

(suedboo!d) ssew punoy 
Pigume 4. Toultions et al

Top $\uparrow$

ORNL-DWG 95Z-4719

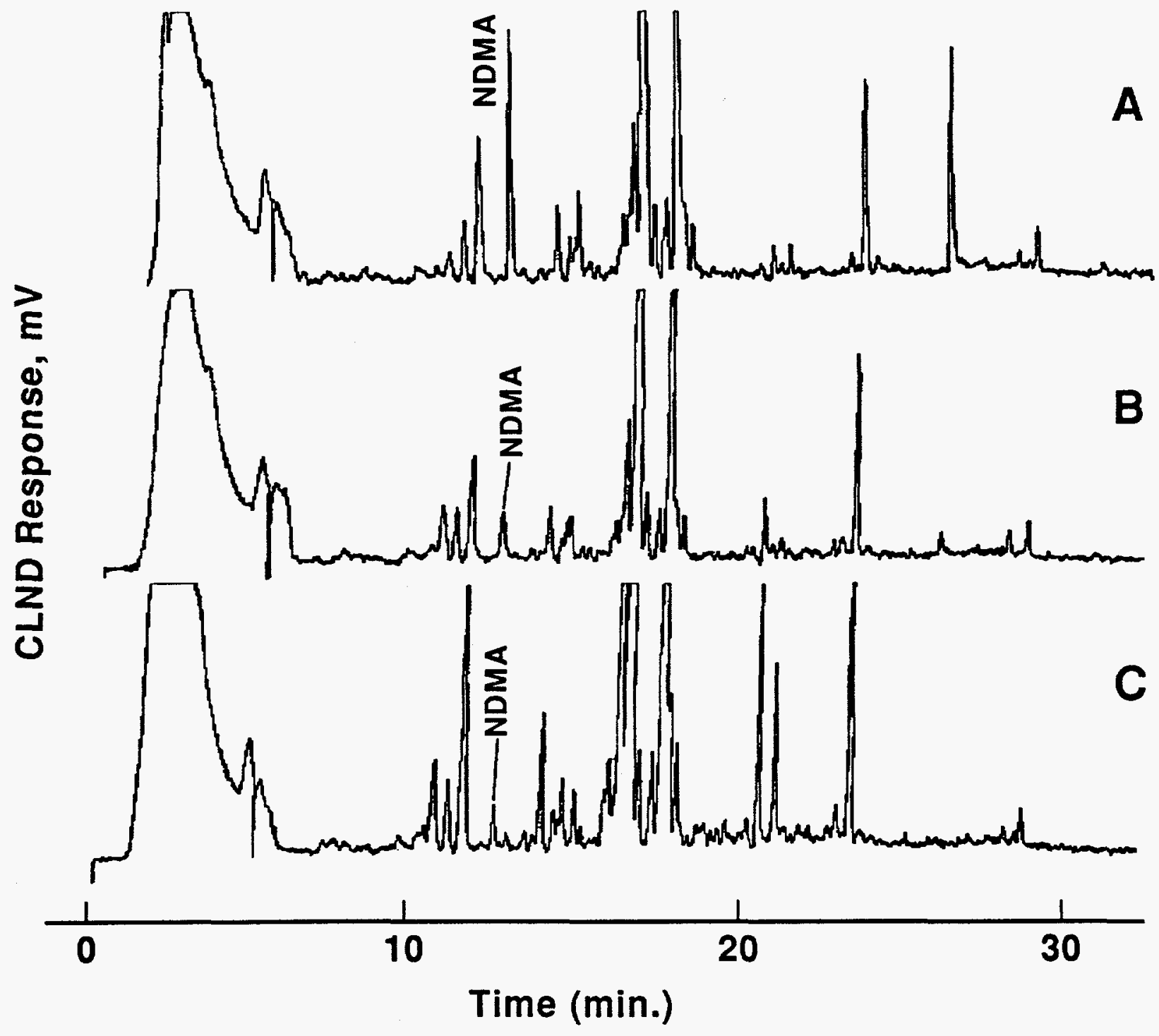


Figures. Toukins stel

$\log \uparrow$

ORNL-DWG 95Z-4720

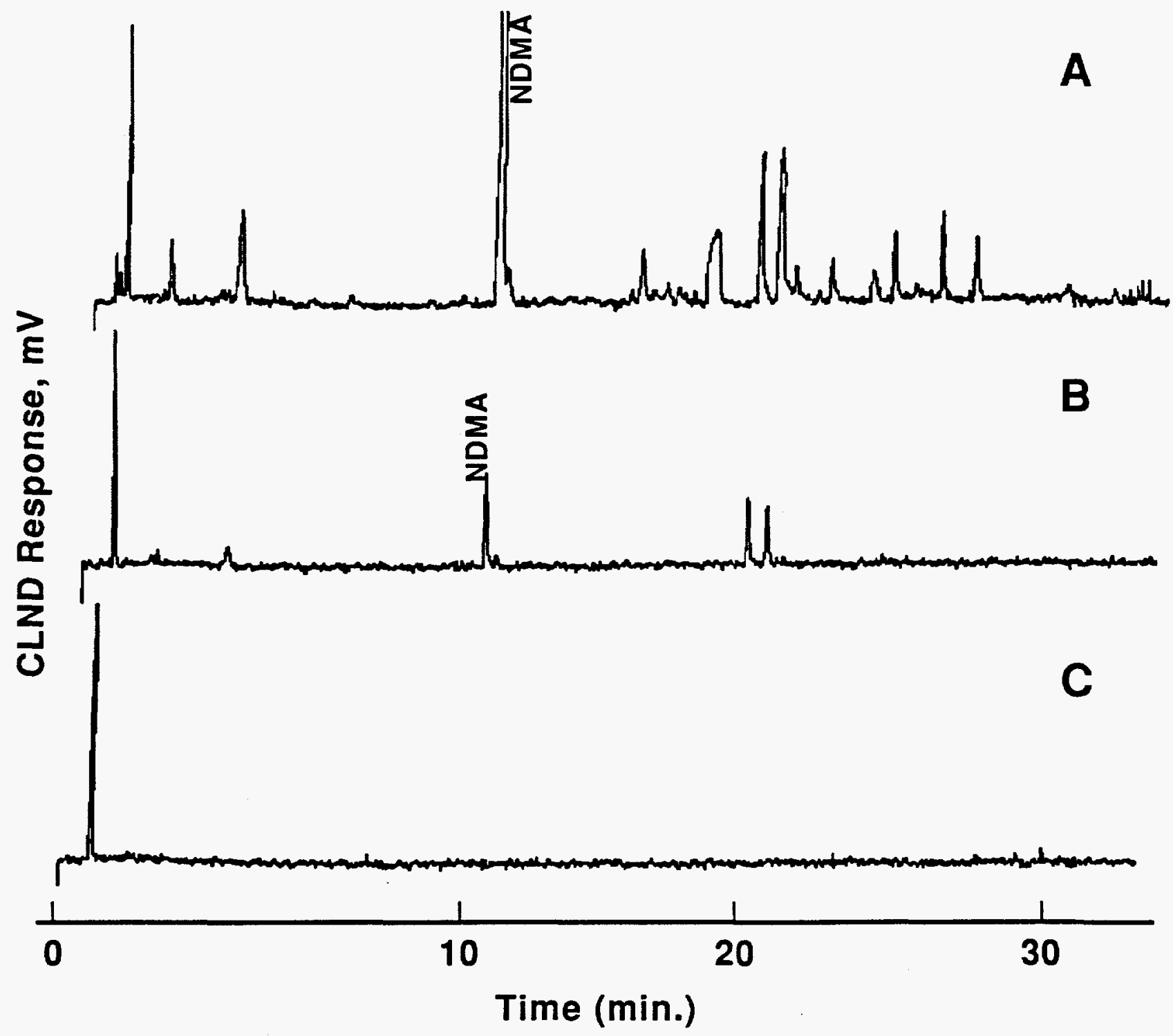




$$
\text { Fisure 6. Tomkins etal }
$$

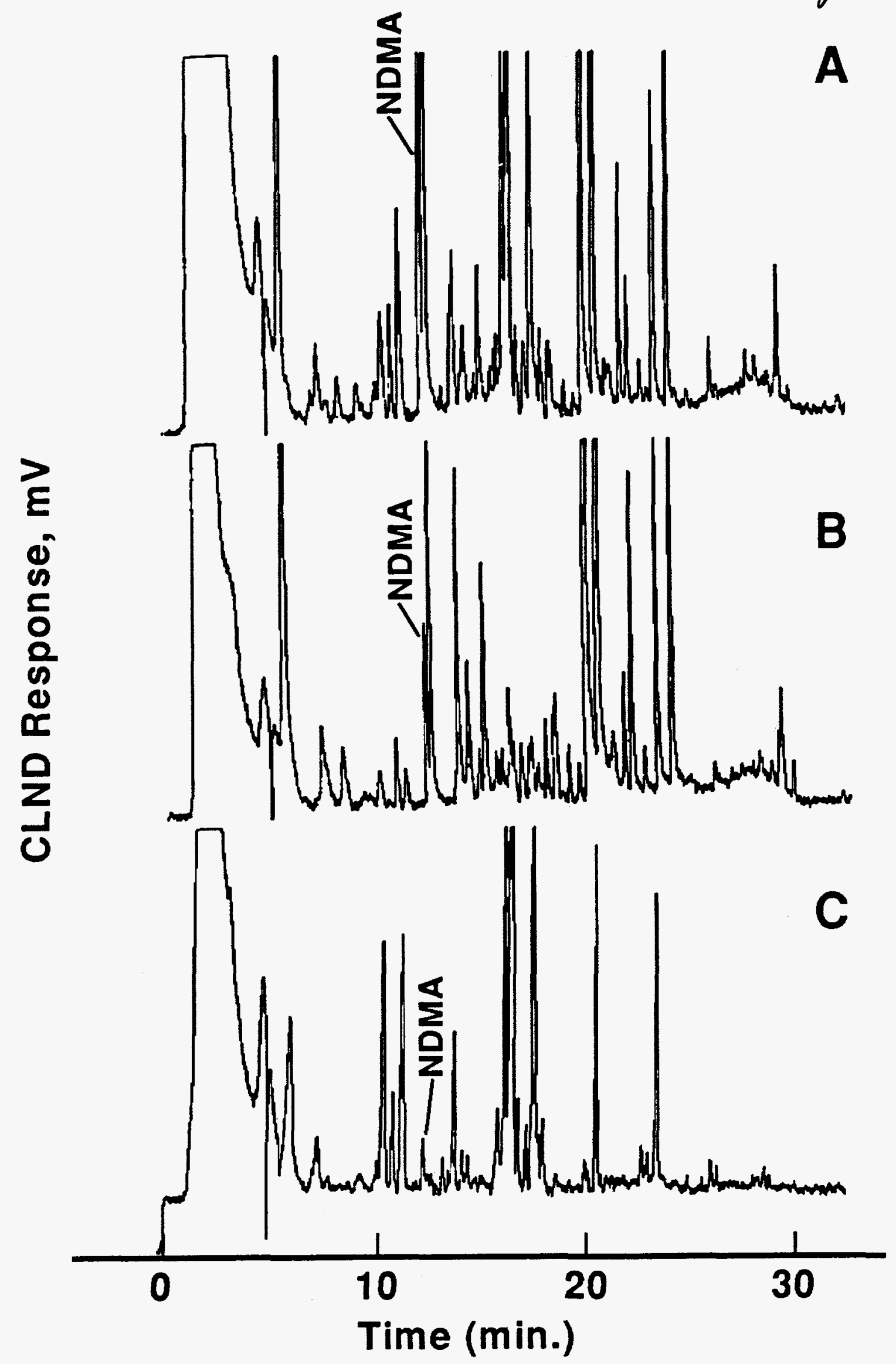

